\title{
Protée
}

\section{Besner le prodigieux}

\section{François Ouellet}

Volume 36, numéro 1, printemps 2008

Le symbole. Réflexions théoriques et enjeux contemporains

URI : https://id.erudit.org/iderudit/018805ar

DOI : https://doi.org/10.7202/018805ar

Aller au sommaire du numéro

Éditeur(s)

Département des arts et lettres - Université du Québec à Chicoutimi

ISSN

0300-3523 (imprimé)

1708-2307 (numérique)

Découvrir la revue

Citer cet article

Ouellet, F. (2008). Besner le prodigieux. Protée, 36(1), 52-58.

https://doi.org/10.7202/018805ar d'utilisation que vous pouvez consulter en ligne.

https://apropos.erudit.org/fr/usagers/politique-dutilisation/ 

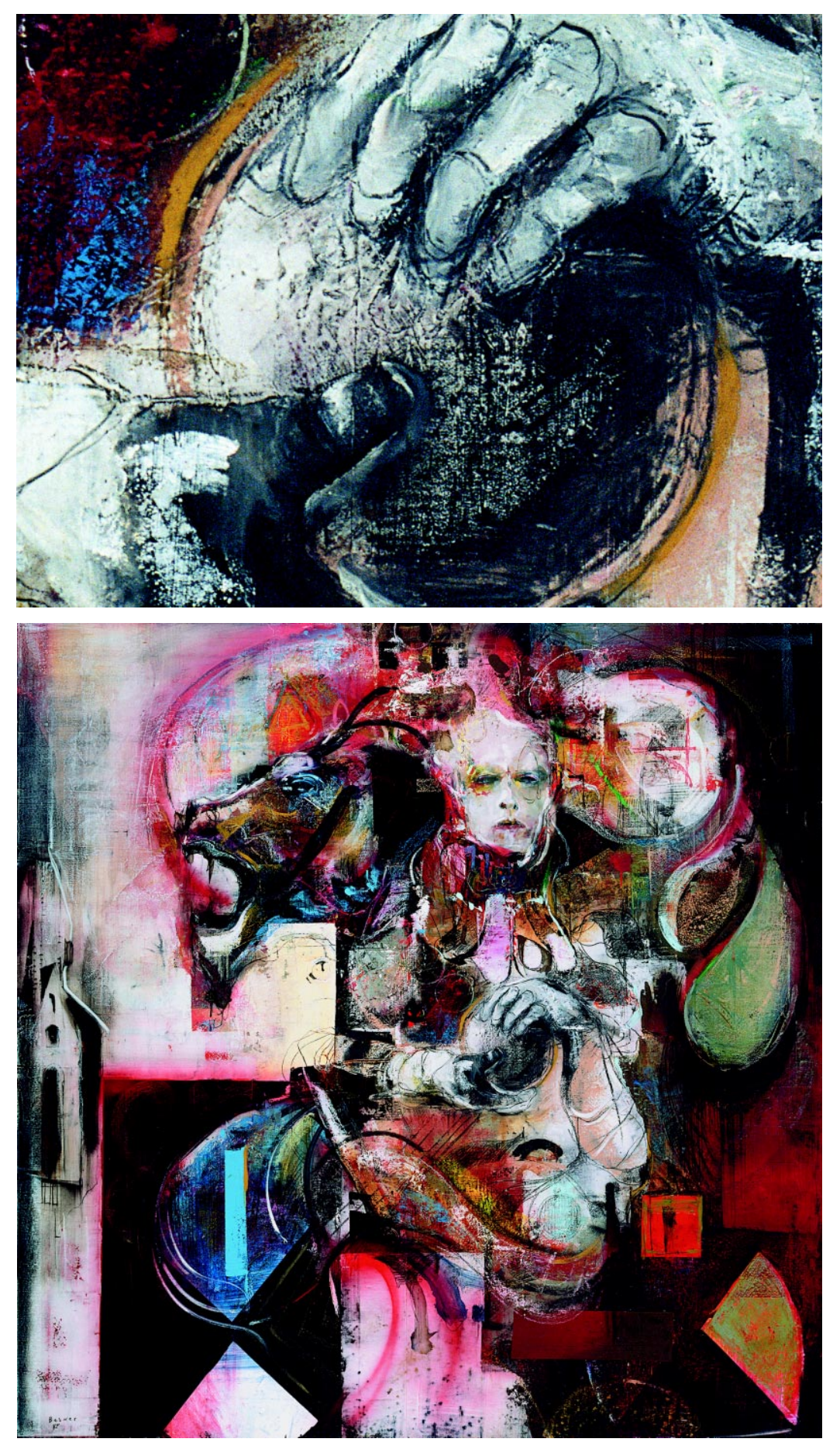


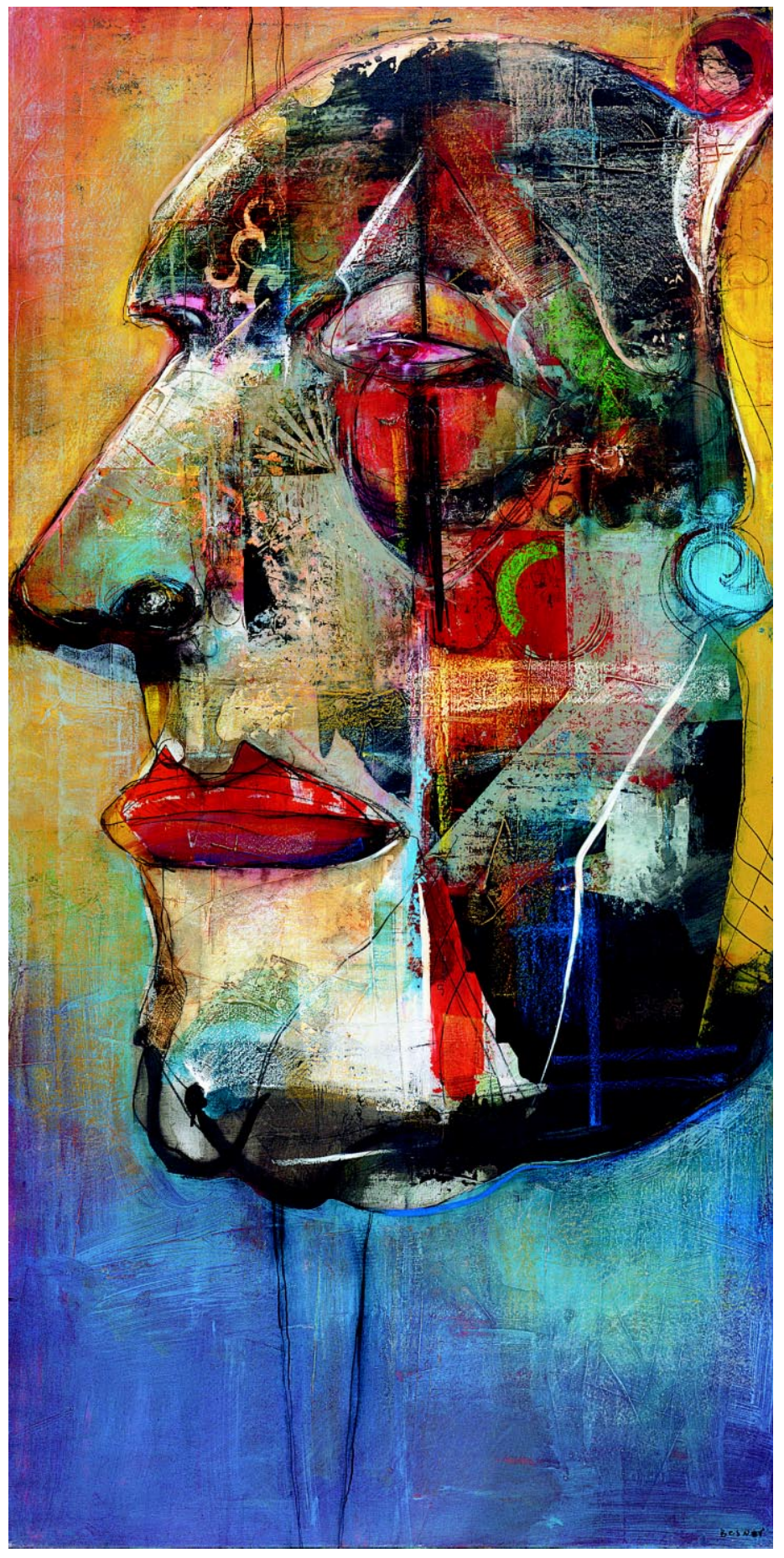




\title{
Besner le prodigieux
}

\author{
U ne présentation de François 0 uellet
}

C

ela aurait été un long roman à travers le temps, où tout commencerait dans le libertinage de fêtes pas si galantes, avec une marquise de Merteuil décrépite mais toujours digne, se démarquant sur les formes vagues de ce qui resterait du carrosse de Cendrillon. Minuit a sonné, elle rendra l'âme au lever du jour et des masques. Au siècle suivant, elle serait Miss Havisham, la fiancée éternellement éplorée de Great Expectations, qui vit recluse depuis vingt-cinq ans au milieu d'objets vétustes et qui porte encore sa robe nuptiale maintenant flétrie et jaunie, comme elle. Plus près de nous, elle aurait joué dans un film exemplaire: Sunset Boulevard, où la star déchue du cinéma muet, Norma Desmond (interprétée par Gloria Swanson), vit dans la gloire des années passées...

Telles sont les toiles des années 1990 qui ont fait la réputation de Dominic Besner et qui ajoutent brillamment à l'histoire du masque, du vice fardé et de la mascarade perverse mais tragique: de vieilles décadentes esseulées, encore excentriques dans leur déchéance corporelle, dont l'expressivité tient d'abord à la tache de l'œil, au visage funéraire, puis aux couleurs dont l'extraordinaire richesse est à la mesure de leur vie outrancière et orgueilleuse. Ces toiles, témoignant d'un aplomb et d'une maîtrise imperturbables dans la composition et la combinaison des couleurs, sonnaient comme un coup de théâtre dans le jeune art contemporain. 
La peinture plus récente de Besner a évolué vers une affirmation encore plus expressive des couleurs et des formes. Les décadentes, sans être complètement absentes, ont fait place à un bestiaire où dominent les coqs et les chevaux qu'on entrevoyait dans les toiles de la série précédente. Les sujets sont représentés de plus près, les visages, les têtes de cheval, les corps massifs, extraordinairement colorés et traversés de traits verticaux et surtout cylindriques, occupent davantage la surface de la toile. La couleur acquiert ainsi une telle importance qu'elle devient le sujet de la toile, c'est elle qui triomphe et, à travers un étalement où le carmin donne souvent le ton, s'offre au regard dans la pureté la plus éclatante, presque aveuglante. Et jamais le moindre signe de couleur ne jure: I'harmonie des couleurs est incomparable.

Besner recourt à une technique mixte, composée notamment de pastel à l'huile, $\mathrm{d}^{\prime}$ acrylique et de crayon, à laquelle s'ajoute le grattage de la toile. À la peinture ou au crayon, Besner trace sur la toile parfois fortement hachurée des formes géométriques qui rappellent sa formation d'architecte. Les toiles ainsi traversées de signes sont riches de toute une préciosité ornementale qui inscrit Besner dans la tradition symboliste de Gustave Moreau, où se mélangent la décadence des corps et celle des civilisations. Malgré une relative abstraction dans la peinture de Besner, il y a là une filiation qu'appellent les sujets représentés, l'éclat des coloris, le marquage hiéroglyphique de la toile, la volonté érudite d'approfondir ce qui se joue sur la scène du désir. Il y a surtout, chez Besner, la souveraineté d'une peinture promise aux plus grands honneurs. 


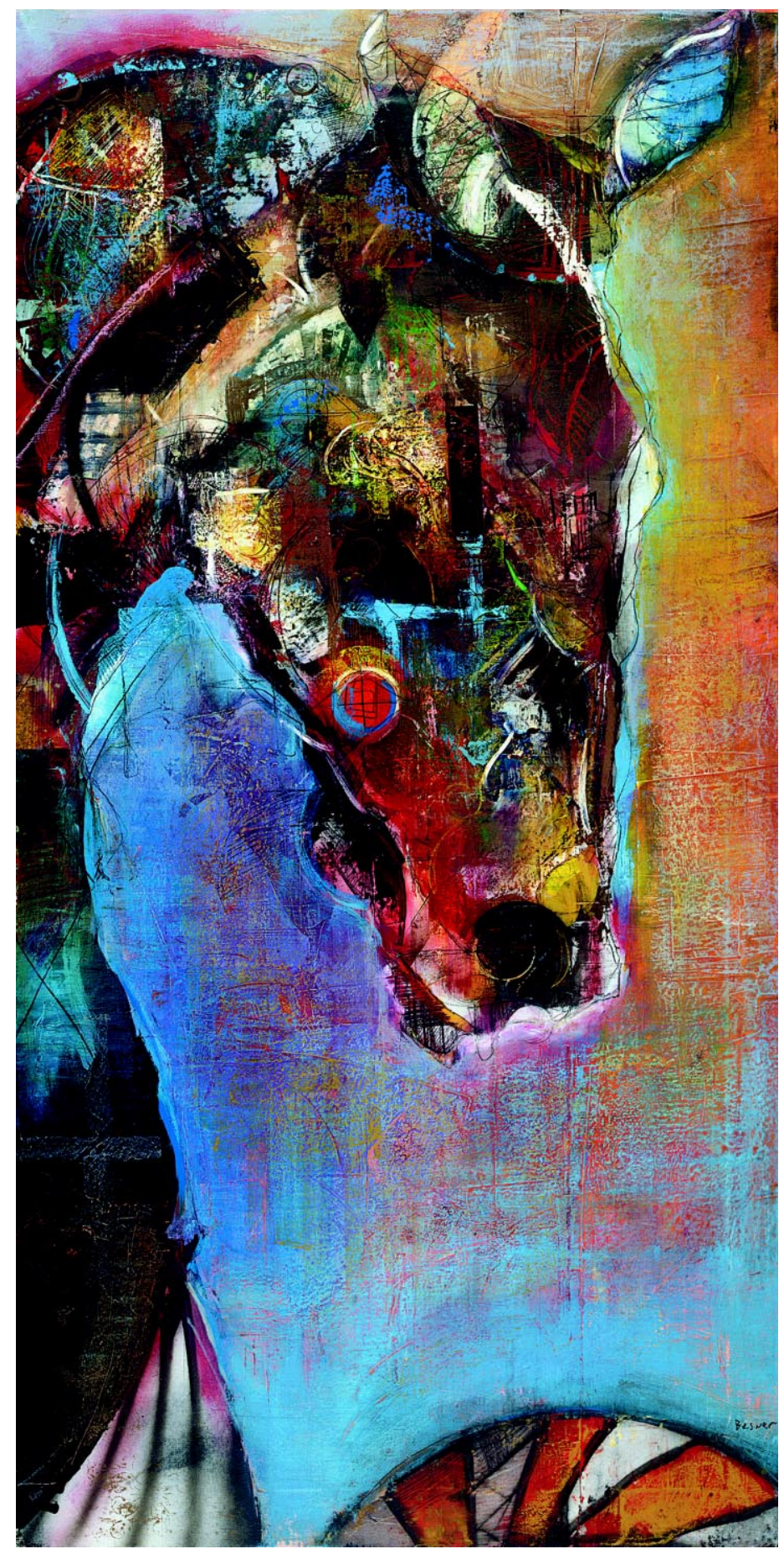



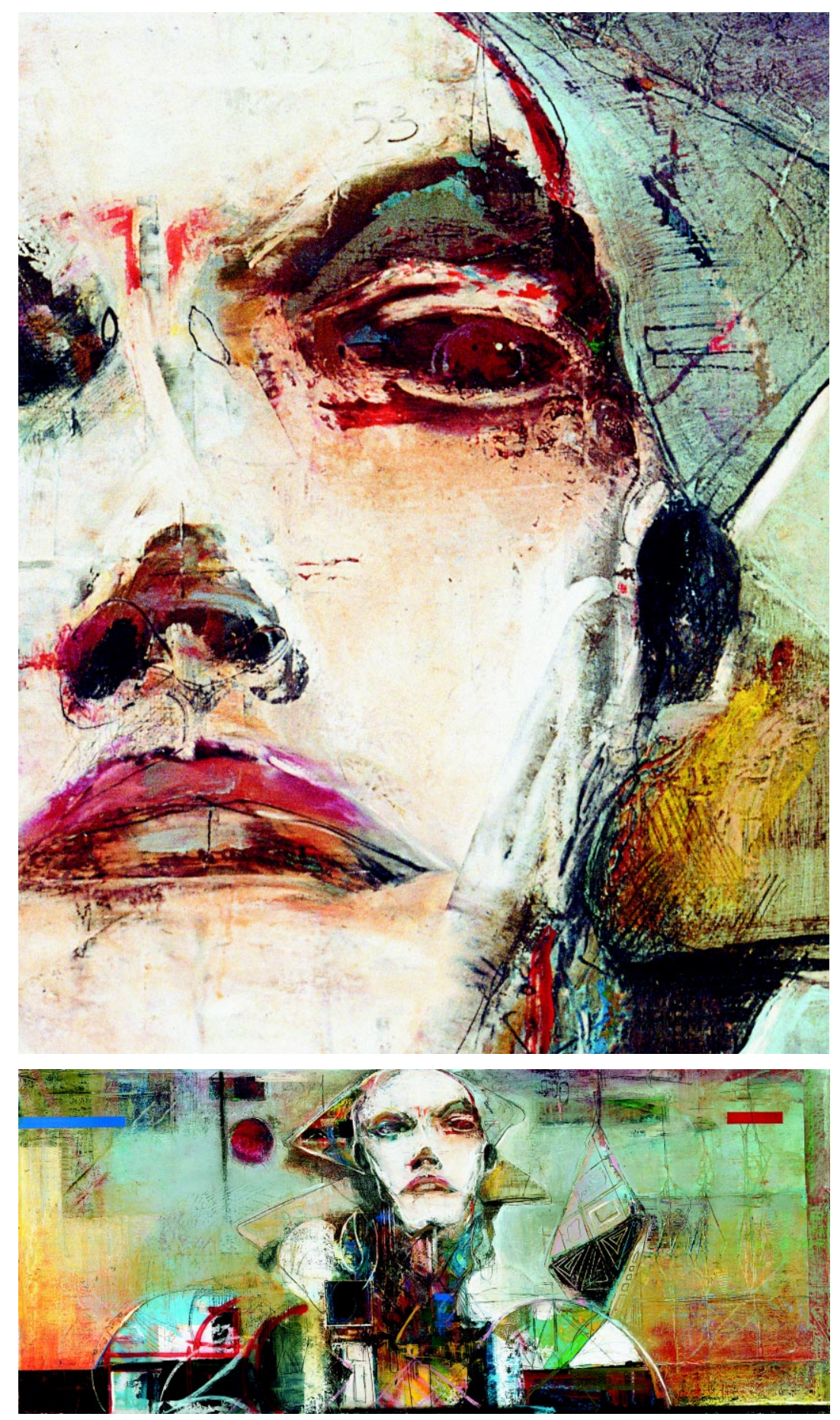
Dominic Besner 2000-2004

\section{page 52 les derniers cris d'une brise techniques mixtes sur toile $152 \times 152 \mathrm{~cm}$}

page 53 trois jeunes tambours

techniques mixtes sur toile $183 \times 91 \mathrm{~cm}$

page 56 à la cadence du jacquemart techniques mixtes sur toile $183 \times 91 \mathrm{~cm}$

page 57 au quai des voceri

techniques mixtes sur toile $91 \times 213 \mathrm{~cm}$ 